\title{
A Contribuição da Pesquisa Avaliação para o Processo de Implementação do Controle Social no SUS'
}

\section{The Contribution of Evaluation Research for the Process of Implementation of Social Control in SUS (National Health System)}

\author{
Adriana Aparecida Batista \\ Mestre em Extensão Rural. \\ Endereço: Av. Nossa Senhora das Graças, 314/102, CEP 35430-214, \\ Ponte Nova, MG, Brasil. \\ E-mail: adrianabatista®terra.com.br \\ José Norberto Muniz \\ Ph.D. em Sociologia. Professor titular do Programa de Mestrado \\ em Extensão Rural na Universidade Federal de Viçosa. \\ Endereço: Av. P.H. Rolfs, s/n, CEP 36570-000, Viçosa, MG, Brasil. \\ E-mail: nmunizœufv.br \\ José Ambrósio Ferreira Neto \\ Doutor em Desenvolvimento, Agricultura e Sociedade Professor \\ associado II do Departamento de Economia Rural da Universidade \\ Federal de Viçosa. \\ Endereço: Av. P.H. Rolfs, s/n, CEP 36570-000, Viçosa, MG, Brasil. \\ E-mail: ambrosioळufv.br

\section{Rosangela Minardi Mitre Cotta} \\ Doutora em Saúde Pública \\ Professora adjunta do Departamento de Nutrição e Saúde da \\ Universidade Federal de Viçosa. \\ Endereço: Av. P.H. Rolfs, s/n, CEP 36570-000, Viçosa, MG, Brasil. \\ E-mail: rmmitreœufv.br
}

\section{Resumo}

Este artigo foi desenvolvido com base nos resultados da aplicação dos pressupostos teóricos da pesquisa de avaliação, no processo de implementação de uma política na saúde no município de Ponte Nova, Minas Gerais. Para isso, contextualizaram-se as políticas aplicadas ao campo da saúde pública a partir da década de 1970, por meio de dois eixos complementares: a Constituição Federal de 1988 e as Leis Orgânicas da Saúde 8.08o e 8.142 de 1990, que criaram e regulamentaram o Sistema Único de Saúde (SUS). Para obter as informações necessárias à análise, tornou-se importante a identificação de indicadores que explicitassem as várias formas de participação dos membros de todas as categorias no Conselho, sendo essas categorias governo, trabalhadores da saúde, prestadores de serviços e usuários. Com esse objetivo, foram analisadas as atas das reuniões do Conselho, de julho de 2003 a junho de 2005. Dentre os resultados obtidos nesta pesquisa, destacam-se as formas de participação dos membros do Conselho, identificadas a partir de indicadores como: esclarecimentos, propostas, sugestões, medidas, indagações, apresentação de resultados, avisos, reclamações, deliberações, denúncias e comentários. Cada um desses indicadores foi analisado com relação às categorias representadas no Conselho: governo, trabalhadores na saúde, prestadores de serviços e usuários. Essa análise revelou as formas de participação dos conselheiros nas reuniões, ou seja, a maneira como cada categoria atua nesse espaço democrático.

Palavras-chave: Pesquisa de avaliação; Controle social; Conselho de saúde; Política pública. 


\section{Abstract}

This article was written based on the results of the application of the evaluation research in the process of implementation of a health policy in a town in the State of Minas Gerais, Ponte Nova. For this purpose, we used the theoretical presuppositions of the process evaluation research. It was contextualized the policies applied to the public health field from the 1970s through two complementary axes: the Federal Constitution of 1988 and the Health Organic Laws, 8.080 and 8.142 from 1990 , which create and regulate the Sistema Único de Saúde (SUS). In order to obtain the necessary information to the analysis, it is important to identify the indicators, which explain the several forms of participation of the members of all categories in the Council: government, health workers, professionals and users. For this proposal, the minutes of the meetings of the Council were analysed from July 2003 to June 2005. Among the results obtained in the research, we can point out the forms of participation of the members of the Council, identified through indicators like clearances, proposals, suggestions, measures, questions, presentation of results, notices, complaints, deliberations, indictments and comments. Each of these indicators were analysed in relation to the categories represented in the Council: government, health workers, professionals and users. This analysis revealed the forms of participation of the counsillor in the meeetings, that is, the way each category acts in this democratic institution.

Keywords: Research Evaluation; Social Control; Health Council; Public Policy.

\section{Introdução}

O Movimento de Reforma Sanitária no Brasil, intensificado na década de 1980 , foi inserido num cenário de redemocratização do país em que a sociedade civil passou a desempenhar seu papel na cena política. 0 marco histórico desse processo foi a VIII Conferência Nacional de Saúde no ano de 1986, resultando no relatório que constituiu a referência para a elaboração da Constituição de 1988. A partir dessa Constituição, institui-se o conceito de universalidade e equidade, passando o Estado a ter o dever de prover políticas econômicas e sociais que visem à qualidade de vida da população, além de inscrever a saúde no campo da seguridade social.

De acordo com Martins e colaboradores (2008), a participação social foi discutida nessa conferência na perspectiva de inserir a população na determinação, no acompanhamento e na fiscalização das políticas de saúde em todas as esferas públicas (federal, estadual e municipal). Desta forma, Valla (1993) defende a ideia de que a participação popular deve ser institucionalizada nos órgãos e serviços do Estado. Para ele, a participação é o instrumento de governo mais adequado para construir um regime democrático, e o Estado deve criar um "conjunto de mecanismos participativos, visando à incorporação dos cidadãos aos programas de governo local”. A participação em Conselhos Municipais pode ser entendida por meio dessa abordagem de Valla, que chama atenção para a contradição existente nessa forma de participação, que, de um lado, legitima a política do Estado diante da população e, de outro, significa um canal para as entidades populares disputarem o controle e a destinação da verba pública (Presoto e Westphal, 2005).

Portanto, o Conselho de Saúde, em caráter permanente e deliberativo, é um órgão de instância colegiada e tem por finalidade consolidar uma das diretrizes da política do SUS, a participação da comunidade. Atua na formulação e no controle da execução da política de saúde, incluindo elementos econômicos e financeiros, ou seja, é a instância que visa a assegurar o controle social da política entendido como o ato de participar da elaboração e implantação das ações de saúde, assim como fiscalizar as ações e o destino dos recursos financeiros nessa área (Oliveira, 2005). 
Entretanto, essas políticas se concretizam pelo planejamento de programas de intervenção, para os quais se encontram várias definições, porém mantendo uma convergência na sua natureza. Dessa forma, política é definida por Weiss (1972) como uma declaração oficialmente aceita de metas ligadas a um grupo de atividades planejadas para realizar ações em uma determinada jurisdição. Sob a proposição de intervenção planejada, não apenas fundamentada em diretrizes gerais, as decisões devem ser coerentes com as metas que guiam os princípios para uma intervenção, e essa vinculação constitui uma das características da política que permite a elaboração de um programa (Kahn e col.;Owen e Rogers, 1999).

Entre definir políticas, instituir programas e projetos e a introdução da avaliação dessas intervenções notam-se, ao mesmo tempo, complementaridades e conflitos. Inicialmente, a complementaridade entre as fases constituintes de uma política decorre da identificação de sua estrutura, permitindo que as intervenções possam ser objeto de avaliação, pois, como admitem Freeman e Bernstein (1975), essas intervenções nem sempre são concebidas para serem avaliadas. Com relação aos conflitos, eles emergem pela forma como tomadores de decisão sobre as intervenções interagem e criam expectativas sobre as proposições apresentadas pelos avaliadores. Portanto, elaborar propostas de avaliação requer, principalmente, a contextualização do objeto a ser avaliado e, posteriormente, a redução de conflitos na esfera administrativa da atividade avaliativa, conforme propõe Weiss (1972).

Entre as alternativas apontadas pelos vários autores pesquisados, pode-se considerar a de Freeman e Bernstein (1975) sobre a avaliação do processo. Para esses autores, essa avaliação permite identificar se o programa ou a política têm sido implementados de forma a atingir seus objetivos.

Apesar da afirmação de Freeman e Bernstein (1975), corroborada por Cohen e Franco (1993), de que as intervenções não estão sendo concebidas e estruturadas para serem avaliadas e, por isso, não é possível saber se os objetivos para os quais foram criadas estão sendo alcançados, Weiss (1972) argumenta que, historicamente, a pesquisa de avaliação tem sido vista como um instrumento, uma ferramenta adicional para os tomadores de decisão. Isso é enfatizado por Wholey e colaboradores (1976), segundo os quais a avaliação não só evidencia resultados, mas, a partir destes, é possível inferir estratégias para que os programas possam alcançar seus objetivos.

Diante dessas definições e assumindo a importância do Conselho Municipal de Saúde (CMS) como órgão estratégico para a descentralização e operacionalização da política de saúde por meio da participação da comunidade, este artigo tem por objetivo descrever e avaliar o processo de implementação dessa diretriz da política do SUS, o Conselho, no município de Ponte Nova, MG.

\section{Metodologia}

A importância desse estudo caracteriza-se pela descrição e avaliação do processo de implementação do Conselho Municipal de Saúde de Ponte Nova-MG, durante o período de julho de 2003 a junho de 2005 , mais precisamente o que foi concebido e implementado para essa instância. Esse processo foi analisado a partir dos princípios e diretrizes do Sistema Único de Saúde (SUS), especificamente em relação à descentralização e à participação da sociedade no controle social e na elaboração e implantação das políticas de saúde do município de Ponte Nova.

A fim de obter informações para análise do processo de implementação da política do SUS através da operacionalização do CMS no município em estudo, no que se refere à participação da comunidade como controle social, a pesquisa fundamentou-se nas seguintes fontes: levantamento bibliográfico sobre experiências de gestão participativa; pesquisa documental em leis que criam o CMS e seu regimento interno e em leis que dispõem sobre a participação da comunidade na gestão do SUS e que regulam as ações e serviços de saúde e atas das reuniões do CMS e da Conferência Municipal de Saúde de Ponte Nova; e na observação direta, por meio da participação na Conferência de Saúde e em reuniões do CMS de Ponte Nova.

Diante dos pressupostos que fundamentaram a investigação, tornou-se importante a identificação de indicadores que nortearam a observação empírica, como o perfil das representações, sua forma 
de apresentação e seu conteúdo. Para identificação desses indicadores, foi realizada uma análise das Atas das reuniões do Conselho durante o período de um mandato, iniciando em julho de 2003 e encerrando em junho de 2005 (mandato mais recentemente concluído para a data em que a pesquisa foi realizada). Todas as informações descritas nas atas das reuniões foram agrupadas de acordo com as categorias representadas no Conselho, ou seja, relacionadas aos gestores, aos trabalhadores da saúde, aos prestadores de serviços e aos representantes da população usuária. A fim de elaborar os indicadores para avaliar o processo de implementação da política em questão, foram consideradas as pautas das reuniões redigidas em forma de atas, as quais registram as participações dos conselheiros por meio de indagações, sugestões, esclarecimentos, denúncias, propostas, medidas, resultados, comentários, avisos, reclamações e deliberações.

\section{Resultados e Discussão}

Um dos objetivos do estudo foi descrever a composição, representação e participação dos membros do Conselho Municipal de Saúde de Ponte Nova-MG, como uma das estratégias da avaliação do processo de implementação da política do controle social no município, pois se existem atribuições de funções para essa instância colegiada, é necessário demonstrar a atuação de seus membros, contrastando com a estrutura organizacional e conceitual apresentada a esse segmento pelos princípios e fundamentos da política do Sistema Único de Saúde (SUS).

\section{Composição do Conselho}

O Conselho Municipal é constituído de 50\% de representantes gestores (municipal e estadual), prestadores de serviços e trabalhadores da saúde; os outros 50\% são representantes da população usuária dos serviços da rede SUS, os quais se originam de várias regiões do município. Essa composição segue adequadamente as diretrizes da política, ressaltando que, de acordo com a Resolução $n^{\circ}$. 333/o3 do SUS, para a formação dos conselhos em relação ao segmento do governo, propõe-se que esta formação seja semelhante à dos conselhos estaduais, desde que adaptada à realidade local, sendo, portanto, desnecessária a presença do representante do governo federal. Dessa forma, constata-se que a composição desse Conselho está em conformidade com as diretrizes da resolução do Conselho Nacional de Saúde, o que será detalhadamente analisado no item seguinte.

\section{Identificação dos Componentes}

O Conselho Municipal de Saúde de Ponte Nova-MG possui representantes da população usuária, dos gestores, dos prestadores de serviços e dos trabalhadores da saúde. Quanto ao segmento dos gestores, constatou-se que os representantes dos governos municipal e estadual são indicados pelo Prefeito. Constituem esse segmento as secretarias de Saúde, de Educação e Cultura, de Ação Social, de Obras e Órgão de Saneamento, Órgãos de Agricultura e o representante do Estado no município, Gerência Regional de Saúde (GRS).

Com relação aos representantes das instituições prestadoras dos serviços públicos e privados, eles são indicados pelos administradores das respectivas instituições, conforme interesses próprios. Dentre essas instituições, estão os hospitais existentes no município e a rede de apoio e diagnóstico credenciada, que advém de clínicas e laboratórios conveniados com o SUS.

Quanto aos representantes dos trabalhadores da área de saúde, eles se constituem dos profissionais de nível médio e superior das diversas áreas da rede pública. Esses membros são eleitos ou indicados por categoria profissional, de nível superior e nível técnico, lotados nos serviços da rede municipal e devidamente registrados em seu conselho regional.

Com relação aos representantes da população usuária, os membros são eleitos entre os usuários do SUS e devem estar vinculados a uma instituição social (como as associações e os conselhos de bairros, as entidades, as comissões, as pastorais etc.). Cada um desses candidatos representa uma zona sanitária do município, e eles devem estar vinculados a uma das várias entidades sociais existentes.

Tanto pela representação das categorias quanto pelo número desses representantes, o Conselho analisado está constituído em conformidade com as diretrizes da política do SUS.

Por essa análise, constatou-se que o Conselho 
Municipal de Saúde de Ponte Nova-MG tem representação paritária na sua composição quanto à categoria dos usuários, ou seja, estes representam 50\% do Conselho.

Do mesmo modo, na composição dos conselhos de saúde de todos os níveis há representantes eleitos por cada um dos principais segmentos da sociedade. Dessa forma, o "pluralismo" é a primeira característica exigida em lei, sendo o que garante a força dos Conselhos. Quando, por motivos diversos, o equilíbrio do pluralismo começa a perder força e algum segmento predomina sobre os demais, sejam usuários, trabalhadores da saúde, prestadores de serviços ou o próprio governo, o Conselho se enfraquece (Santos, 200o).

\section{Caracterização da participação no Conselho}

A categorização da participação dos membros do Conselho ocorre de duas formas: a primeira, relacionada à frequência às reuniões plenárias; e a segunda, à participação em tópicos específicos que foram discutidos ao longo das reuniões plenárias.

De acordo com as informações obtidas no livro de presença das reuniões, durante o período de julho de 2003 a junho de 2005, que corresponde a um mandato do Conselho, constatou-se que há variações na frequência dos membros nas reuniões. Considerando que no mês de janeiro o Conselho está de recesso, a variação na frequência ocorre, principalmente, em relação ao número de conselheiros que compõem o Conselho e ao número de conselheiros que participam das reuniões. Portanto, a frequência desses representantes contou, em média, com 21 membros, sendo que o Conselho possui 68. Assim, pode-se inferir que apenas $31 \%$ dos representantes do Conselho frequentaram as reuniões no período investigado. Entretanto, constatou-se grande variação na presença dos membros na plenária nos meses de dezembro de 2004 (78 participantes) e março de 2005 (52 participantes), cuja participação foi muito maior do que a média. Esse dado pode estar relacionado ao fato de que, em dezembro de 2004, se deu a finalização do mandato do prefeito e, consequentemente, mudança de governo, com recente divulgação dos resultados do processo eleitoral. Na reunião de março de 2005, de acordo com as informações descritas na ata, houve extensa discussão sobre o planejamento do gestor para o setor da Atenção Básica, à qual se destina o Programa Saúde da Família, que desenvolve ações de promoção e prevenção à saúde da população. Isso pode facilitar a compreensão sobre o aumento do número de participantes na plenária do Conselho.

No que se refere à baixa frequência dos conselheiros às reuniões, ela revela algumas das dificuldades no processo de consolidação do Conselho como espaço para o exercício da democracia e concretização dos princípios do SUS. Assim, esses baixos percentuais de frequência dos membros às reuniões apontam algumas tendências no comportamento desses representantes que evidenciam:

- o insuficiente comprometimento dos conselheiros ausentes com a população que eles representam;

- a carência de informações sobre as atribuições dos conselheiros e quanto às normas que regem o funcionamento interno desse fórum, que, para as ausências, prevê substituição do representante após três faltas consecutivas não justificadas;

- a falta de entendimento do que seja controle social por parte dos membros do Conselho, que pode ter origem na deficiente construção de uma cultura participativa, o que Baquero (2001) relaciona a "uma suposta incapacidade da sociedade em se mobilizar autonomamente para fiscalizar e modificar o processo político".

Com relação à segunda forma de participação, o conteúdo das participações foi agregado em categorias ou indicadores, conforme o tipo da participação. Para exemplificar, os indicadores de participação foram os seguintes: apresentação de sugestões, pedir e fazer esclarecimentos, proferir denúncias, manifestar propostas, propor medidas, exibir resultados, fazer comentários e indagações, comunicar avisos, realizar reclamações e efetivar as deliberações (Tabela 1).

Ao todo foram identificados 11 indicadores, e a participação que requer esclarecimentos é aquela que ocorre com maior frequência em todas as reuniões. No total, foram 91 manifestações por meio de esclarecimentos, 34\% do total de 267 participações. Vale destacar que um alto índice de esclarecimentos revela, implicitamente, um alto índice de questionamentos. Isso é esperado, já que esse fórum se caracteriza por ser um local para a ocorrência desses debates. 
Tabela I - Participação dos representantes do Conselho Municipal de Saúde de Ponte Nova-MG, por categoria, no período de julho de 2003 a junho de 2005

\begin{tabular}{|c|c|c|c|c|c|}
\hline \multirow{2}{*}{ Categorias } & \multirow{2}{*}{$\frac{2003}{2^{0} . \text { semestre }}$} & \multicolumn{2}{|c|}{2004} & \multirow{2}{*}{$\frac{2005}{I^{0} . \text { semestre }}$} & \multirow{2}{*}{ TOTAL } \\
\hline & & $1^{\circ}$. semestre & $2^{0}$. semestre & & \\
\hline Esclarecimento & 21 & 28 & 15 & 27 & 91 \\
\hline Deliberação & 13 & 16 & 13 & 17 & 59 \\
\hline Proposta & 8 & 6 & 5 & 10 & 29 \\
\hline Indagação & 7 & 8 & 4 & 5 & 24 \\
\hline Comentário & 10 & 9 & 3 & 0 & 22 \\
\hline Medida & 3 & 5 & 1 & 2 & $"$ \\
\hline Sugestão & 2 & 4 & 2 & 1 & 9 \\
\hline Resultado & 4 & 3 & 1 & 0 & 8 \\
\hline Reclamação & 3 & 3 & 0 & 0 & 6 \\
\hline Denúncia & 0 & 2 & 0 & 2 & 4 \\
\hline Aviso & 1 & 0 & 3 & 0 & 4 \\
\hline
\end{tabular}

Mais especificamente, os esclarecimentos foram divididos em três conteúdos distintos: como explicações a questionamentos de reuniões anteriores, prestadas pelo secretário de saúde; como esclarecimentos sobre as indagações e dúvidas que surgiram durante as reuniões, apresentados pelos demais membros; e os esclarecimentos pertinentes à pauta da reunião do mês.

Das 91 participações na forma de esclarecimentos, $90 \%$ das explicações foram prestadas pelo secretário de saúde e as 10\% restantes foram questões que surgiram durante a reunião, proferidas, em primeiro lugar, pelos representantes dos usuários, seguidos dos prestadores de serviços, que são as categorias que mais manifestaram esse tipo de participação.

Dessa forma, os esclarecimentos nem sempre decorrem de perguntas, pois as pendências que permanecem sem resposta nas reuniões anteriores são, normalmente, transferidas para a próxima reunião. Isso acontece quase sempre por iniciativa da gestão, sem que os demais representantes solicitem. Esses dados demonstram que as reuniões são praticamente direcionadas de acordo com o planejamento do gestor, que também ocupa o cargo de presidente do Conselho.

Para melhor compreensão, os esclarecimentos foram divididos em seis áreas: infraestrutura, assistência, recursos humanos, materiais de consumo, alocação de recursos e projetos. Os representantes dos usuários abordam problemas relativos à área de materiais de consumo, como provisão de medicamentos; de assistência, como funcionamento de serviços especializados, incluindo consultas e exames; de projetos, demonstrando interesse em esclarecer as dificuldades nos processos de implantação dos projetos que aprovaram; de infraestrutura, como reformas e construções de área física ou mudanças nos locais de atendimento; e de recursos humanos, como treinamento, capacitação e contratação de pessoal para melhorar o atendimento aos usuários. Por sua vez, os prestadores de serviços abordam problemas das áreas de administração e gerenciamento, que incluem alocação de recursos; de projetos, sendo esses do interesse da instituição que representam; de recursos humanos, como treinamento e capacitação de pessoal; de materiais de consumo; e de infraestrutura, como conserto de equipamentos diagnósticos (por exemplo, aparelho de raios X).

A segunda forma de participação mais frequente é a deliberação. São 59 participações, 22\% no total de 267 , bem inferior à frequência de ocorrência dos esclarecimentos. Entretanto, a soma das duas frequências de participações atinge $56 \%$ das 267 , revelando o principal comportamento dos membros nas plenárias. 
Para fins de análise, esse indicador foi definido, primeiro, como deliberações obrigatórias, aquelas que não podem deixar de ocorrer, que incluem aprovação de ata anterior e aprovação da prestação de contas do mês anterior. Em segundo lugar, estão os credenciamentos, cadastramentos, convênios, programas, projetos e demais atribuições do Conselho. A maior parte dessas deliberações constitui as propostas que foram aprovadas na Conferência Municipal de Saúde, com a participação da população, e que passaram a integrar o Plano Diretor do município. As demais aprovações reúnem (re)cadastramentos a programas e projetos do Ministério da Saúde para desenvolvimento local. Deve-se ressaltar que as deliberações ocorrem por meio do voto da maioria na plenária.

As propostas compõem a terceira forma de participação dos membros do Conselho, constituindo-se de 29 participações, $11 \%$ em relação ao total. A natureza das propostas discutidas nas reuniões divide-se em três conteúdos: os relacionados à infraestrutura, aos recursos humanos e aos materiais de consumo. Dentre esses conteúdos, as demandas dos representantes surgem conforme interesses próprios, como a dos representantes dos prestadores, que apresentam propostas visando à implantação de serviços no município que serão conveniados a eles ou à avaliação de dívidas do Estado ou do município com essas instituições. Com relação aos representantes dos usuários, as propostas dirigem-se à necessidade de agilizar os processos de implementação dos projetos deliberados por eles, e esses projetos se referem à área da atenção básica, que compreende projetos como o PSF. Basicamente, as propostas expressam ações que podem minimizar os problemas que dificultam o acesso dos usuários aos serviços do SUS.

A partir dessas informações, constatou-se que outro indicador de participação que pode gerar propostas são as reclamações, apresentadas por seis participações durante o período estudado, $2 \%$ no total de 267. As seis reclamações foram levadas ao Conselho pelos representantes dos usuários. 0 conteúdo das reclamações se constitui de problemas nas áreas da assistência; da infraestrutura, como conserto e aquisição de equipamentos para exames; de recursos humanos, como a presença ou ausência dos profissionais e sua qualificação; e quanto à comunicação interna no Conselho, como mudanças nos horários das reuniões. Nota-se que os esclarecimentos, as propostas e as reclamações se manifestam por meio de conteúdos que envolvem as mesmas áreas, com destaque para infraestrutura, recursos humanos e assistência. Isso demonstra que tais áreas constituem o foco da atenção dos conselheiros, pois esses dados estão registrados nas atas das reuniões e revelam a dinâmica das discussões. Entretanto, as dificuldades na implementação das ações que visam a alcançar os objetivos das propostas aprovadas na Conferência Municipal de Saúde permitem identificar que as propostas podem estar sendo elaboradas de maneira a dificultar o seu entendimento por parte dos conselheiros e que há despreparo desses conselheiros para entender essas propostas de modo a implementá-las com eficiência, impedindo que esses membros compreendam os interesses das coletividades que representam.

Constatou-se que os membros do Conselho se mobilizam de maneira individual, o que demonstra a não existência de uma ação que vise aos interesses coletivos, como, por exemplo, dos segmentos que representam. Dessa forma, identificou-se que tais dificuldades limitam a atuação dos representantes no Conselho e geram obstáculos à implementação da política de controle social. Carvalho (1998) corrobora essa constatação ao afirmar que esses limites na consolidação dos conselhos geram necessidade de melhor avaliação do alcance desses espaços participativos, que possa averiguar a direção desses debates e até que ponto eles promovem os interesses da coletividade.

A quinta forma de participação evidenciada no Conselho é a indagação. Essa forma de participação se expressa por meio de questões concentradas nas áreas da infraestrutura, do gerenciamento do Fundo Municipal de Saúde, dos recursos humanos (como treinamento de pessoal), da assistência, de materiais de consumo e de perguntas que explicitam os interesses de cada categoria representada no Conselho. Geralmente, as perguntas são direcionadas ao presidente do Conselho, que é o Secretário de Saúde, e/ou ao coordenador do setor questionado, o que evidencia a forma de participação dos gestores e de alguns funcionários, sendo esses ocupantes de cargos de chefia. Deve-se explicitar que algumas 
dessas questões se repetem por várias reuniões, sendo essas pertinentes aos setores mais críticos da saúde, como a provisão de materiais, incluindo medicamentos, material para curativo, papel higiênico, água potável etc., que envolvem processos licitatórios.

Considerando o conteúdo dos esclarecimentos e das indagações, é possível identificar que há uma convergência entre ambos os indicadores. Os problemas abordados por meio desses indicadores são de ordem emergencial, como falta de medicamentos ou material básico para o funcionamento dos serviços em seus vários setores (seja na atenção básica ou no setor especializado). Dessa forma, nota-se que o espaço democrático, que tem por função consolidar o controle social da política pública do setor, é utilizado para criar soluções imediatas, pois não há discussões que possibilitem o avanço no desenvolvimento das ações e na prevenção dos problemas crônicos.

Os comentários, avisos, medidas e sugestões constituem formas de participação do Conselho e somam 46 manifestações, $17 \%$ das 267 . Apresentados, na maior parte, pelo representante da gestão, revelam outras formas de participação do presidente do Conselho. A partir da análise desses indicadores, que representam $17 \%$ das participações, constatouse que eles nem sempre constam da pauta e, muitas vezes, acabam se esgotando na mesma reunião em que foram apresentados, não retornando à plenária. Vale ressaltar ainda que algumas medidas constituem adequações que, apesar de não serem estruturadas, ou seja, apresentadas como propostas para deliberação ou não, são consideradas modos de corrigir falhas no sistema.

A exposição de resultados constitui outra forma de participação com 8 manifestações, $2 \%$ do total. Esses valores demonstram que a frequência de ocorrência de resultados é muito inferior à dos esclarecimentos; eles são apresentados, exclusivamente, pelo gestor, constituindo-se de dados sobre as propostas elaboradas nas conferências realizadas, resultados de campanhas de vacinação, de alguns projetos implementados no município, da distribuição de medicamentos nos postos, e o relatório de gestão, com um demonstrativo das ações e dos recursos empregados no ano a que se refere.
Por fim, foram identificadas as denúncias como a forma de participação que apresentou um dos menores percentuais: 4 manifestações representando 1,4\% do total de participações. As denúncias são proferidas, na maioria das vezes, pelos representantes dos usuários, sendo registrada uma participação dos membros prestadores de serviços. O conteúdo das denúncias que foram apresentadas pelos membros da categoria dos usuários constitui-se de irregularidades no atendimento prestado pelos hospitais, no uso dos veículos da Secretaria de Saúde e nas condições desumanas a que estão submetidas algumas famílias. Por sua vez, os prestadores denunciam as irregularidades no processo de descentralização de clínicas especializadas, pois, neste caso, os profissionais envolvidos fazem parte do quadro de funcionários dessas instituições, que também ofertam esse tipo de atendimento.

\section{Considerações Finais}

Diversos atores e fatores influenciam o processo participatório que tem lugar no Conselho Municipal de Saúde. Este trabalho focalizou as características estruturais dessa política de saúde, particularmente no que se refere a seu funcionamento e composição, e o modo como vêm sendo organizadas as ações desenvolvidas no município no tocante à sua concepção. Concepção essa que considerou como componentes de um programa a definição, a estrutura, a organização, a implementação, o monitoramento e a avaliação.

A Constituição Federal de 1988 garante a participação popular no direcionamento e gerenciamento das políticas do Sistema Único de Saúde - SUS. As políticas desenvolvidas a partir desses parâmetros têm obedecido a esses pressupostos em termos de constituição. Desse modo, a regra geral que orienta a composição dos conselhos favorece a que os usuários da área da saúde possam ter mais influência na plenária. Assim, os conselhos de saúde devem ser paritários em termos de número de representantes de usuários, em relação aos demais segmentos participantes.

Ao analisar a atuação do Conselho Municipal de Saúde de Ponte Nova, foram examinadas sua composição, constituição e dinâmica de funcionamento. $\mathrm{Na}$ 
área da saúde, o fórum participatório foi criado em meados da década de 1980, quando se iniciou também o processo de descentralização, que culminou no aumento da importância da esfera municipal da administração pública. Os conselhos de saúde foram criados no início da década de 1990. Em Ponte Nova, o Conselho foi criado pela Lei Municipal 1.63o, em 1991, e representou a institucionalização de um padrão de gestão descentralizada, que consolidava um modo legítimo de envolvimento de usuários nas instâncias participatórias.

A composição do Conselho obedece, em linhas gerais, às determinações legais, sendo a maior proporção de conselheiros da categoria dos usuários, o que resulta em maior influência desses representantes nas suas atividades. Portanto, os horários noturnos das reuniões, a existência de apoio técnico-administrativo (constatado pela presença de alguns técnicos nas reuniões) e o caráter público das reuniões são indicativos de que as atividades são organizadas levando em conta os interesses dos representantes dos usuários. No entanto, a análise dos conteúdos das participações, por meio da definição de indicadores que representam as várias formas de participação dos membros, demonstrou que o Conselho Municipal de Saúde de Ponte Nova, apesar de toda a estrutura e organização favorecer os interesses da coletividade, atua de maneira individualizada quanto aos assuntos debatidos. As propostas apresentadas na plenária, apesar de terem sido pouco discutidas, revelaram problemas que envolvem, de forma reincidente, as mesmas áreas, como a da infraestrutura, da assistência, de materiais de consumo e de recursos humanos. Do mesmo modo ocorreu com os esclarecimentos prestados pelo representante da gestão, o presidente do conselho. Ao mesmo tempo, temas importantes - que muitas vezes envolvem credenciamentos e planejamentos - são discutidos de maneira informal por comentários e sugestões feitos ao final das reuniões, momento em que muitos conselheiros deixam a plenária. Essa dinâmica de funcionamento das reuniões revelou como ocorre a liderança no fórum de discussões. 0 representante da gestão, que é também o presidente do Conselho, participa das reuniões de todas as formas, com exceção do fato de não apresentar denúncias e não fazer reclamações; assim, acaba liderando os debates, pois apresenta a maioria das propostas e presta todos os esclarecimentos.

Partindo do pressuposto de que os gestores detêm mais informações sobre o funcionamento da política de saúde do SUS, conforme revelado pelo modo com que participam das reuniões, conclui-se que uma das maneiras identificadas nesta pesquisa, para que possam, diante dessa realidade, ser amenizados os obstáculos à implementação do Conselho, é a capacitação, que deve ser permanente e ter suas diretrizes traçadas a partir dos resultados da pesquisa de avaliação de processo. Assim, a pesquisa de avaliação de processo será utilizada como estratégia para redefinir o curso de ações em andamento, como, por exemplo, na tentativa de corrigir algumas distorções identificadas por meio da análise desta pesquisa, que avaliou o processo do Conselho $\mathrm{Mu}$ nicipal de Saúde de Ponte Nova.

\section{Referências}

BAQUERO, M. Cultura política participativa e desconsolidação democrática: reflexões sobre o Brasil contemporâneo, São Paulo em Perspectiva, São Paulo, v. 15, n. 4, out.-dez. 2001. Disponível em:<http://www.scielo.br/scielo.php?pid=s0102$88392001000400011 \&$ script=sci_arttext $>$. Acesso em: 28 jan. 2006.

BRASIL. Constituição Federal de 1988 (Seção II - Da Saúde). Disponível em: <http://www.senado. gov.br/legislacao/const/con1988/CON1988_ 05.10.1988/index.shtm>. Acesso em: 03 ago. 2004

BRASIL. Lei n. 8.142, de 27 de dezembro de 1990. Dispõe sobre a participação da comunidade na gestão do Sistema Único de Saúde (SUS) e sobre as transferências intergovernamentais de recursos financeiros na área da saúde e dá outras providências. Disponível em: <http://www. planalto.gov.br/ccivil_o3/Leis/L8142.htm>. Acesso em: 18 set. 2004 . 
BRASIL, Resolução $n^{\circ}$ 333, de o4 de novembro de 2003. Aprova as seguintes diretrizes para criação, reformulação, estruturação e funcionamento dos Conselhos de Saúde. Disponível em: <http:// dtr2004.saude.gov.br/susdeaz/legislacao/ arquivo/72_Resolucao_333.pdf >. Acesso em: 18 set. 2004 .

BRASIL. Ministério da Saúde. Conselho Nacional da Saúde. "Efetivando o Controle Social: apresentação. Disponível em: <http://conselho. saude.gov.br/apresentacao/apresentacao.htm>. Acesso em: 20 jan. 2005.

COHEN, E.; FRANCO, R. Avaliação de projetos sociais. 5. ed. Petrópolis, Rio de Janeiro: Vozes, 1993. p. 19-37.

COSTA, R. C. R. Descentralização, financiamento e regulação: a reforma do sistema público de saúde no Brasil durante a década de 1990. Revista de Sociologia e Política, Curitiba, n. 18, jun. 2002. Disponível em: <http://www.scielo.br/scielo. php?pid=So104-44782002000100005\&script=sci arttext>. Acesso em: 27 out. 2005.

FREEMAN, H. E.; BERNSTEIN, I. N. Academic Entrepreneurial Research: the consequences of diversity in Federal Evaluation Studies. New York: Russell Sage Foundation, 1975. p. 1-31.

MARTINS, P. C. et al. Conselhos de saúde e a participação social no Brasil: matizes da utopia. Physis (Rio de Janeiro), Rio de Janeiro, v. 18, n. 1, p. 105-121, 2008. Disponível em: <http://www.scielo. br/scielo.php?pid=S0103-73312008000100007\&sc ript=sci_arttext>. Acesso em: 15 jun. 2009.
OWEN, J. M.; ROGERS, P. J. Evaluation Program: forms and Approaches International edition. London: SAGE Publications, Thousand Oaks: New Delhi, 1999. p. 1-62.

PRESOTO, L. H.; WESTPHAL, M. F. A participação social na atuação dos conselhos municipais de Bertioga-SP, Saúde e Sociedade, São Paulo, v. 14, n. 1, jan.-abr. 2005. Disponível em: <http://www. scielo.br/scielo.php?pid=So104-129020050001000 o8\&script=sci_arttext>. Acesso em: 15 jun. 2009.

SANTOS, N. R. Implantação e funcionamento dos conselhos de saúde no Brasil. In: CARVALHO, M. C. A. A.; TEIXEIRA, A. C. C. (org.) Conselhos Gestores de Políticas Públicas. São Paulo: Polis, 2000. 144 p.

WEISS, C. H. Evaluation: methods for studying programs and policies. 2. ed. New Jersey: PrenticeHall, Simon \& Schuster/A Viacom Company, Upper Saddle River, 1972. 372 p.

WHOLEY, J. S. et al. Federal evaluation policy: analyzing the effects of public programs. Washington, DC: The Urban Institute, 1976. p. 2227. 